\title{
Synovial fluid white cell count and histopathological examination of periprosthetic tissue samples [frozen and permanent sections] in the diagnosis of prosthetic knee infection
}

${ }^{1}$ Orthopaedic-Traumatology Clinic, Emergency Clinical Hospital of Constanta, Romania

${ }^{2}$ Physical Medicine and Rehabilitation Clinic, Emergency Clinical Hospital of Constanța, Romania

${ }^{3}$ Pathological Anatomy Department, Emergency Clinical Hospital of Constanta, Romania

\begin{abstract}
The aim of the study was to determine prospectively the importance of synovial fluid white cell count and intraoperative frozen and permanent sections analysis (number of polymorphonuclear leukocytes per highpower field) in the diagnosis of septic total knee arthroplasty. There were studied prospectively 72 patients who needed a revision total knee arthroplasty between 2013-2015. 30 patients were diagnosed with prosthetic joint infection due to high rates of ESR (93\%) and CRP (90\%) and preoperative positive culture from aspirated synovial fluid and 42 patients were considered to have aseptic failure according to negative preoperative culture from joint aspirate. For all the patients was analysed synovial fluid white cell count and histopathological aspect of intraoperative frozen and permanent sections of periprosthetic tissue. The results showed a median value of 13800 of sinovial white cells count for infected knee and 92 for noninfected knee. $90 \%$ of the patients with joint infection had more than 5 polymorphonuclear leukocytes per high power field on intraoperative frozen sections and $83 \%$ on permanent sections. None of the patients from aseptic group had more than 5 polymorphonuclear leukocytes per field on permanent sections. The erythrocyte sedimentation rate and C-reactive protein level can be supplemented with cultures of aspirated joint fluid and fluid white cell count to confirm the diagnosis of periprosthetic
\end{abstract}

\section{Bogdan Obada}

Emergency Clinical Hospital

Tomis 145, 900591 Constanta, Romania

email : bogdanobada@yahoo.com infection. When the preoperative diagnosis remain unclear, the histological examination of frozen or permanent sections of periprosthetic tissue with at least 5 polymorphonuclear leukocytes per high power field, is predictive for the presence of infection.

Keywords: knee, arthroplasty, infection, synovial fluid, leukocytes, frozen sections

\section{Introduction}

There is no universally accepted method to distinguish clearly between aseptic and septic loosening in knee arthroplasty. Clinical examination, laboratory studies, plain radiographs and nuclear scans cannot be relied on to demonstrate accurately the presence or absence of infection [1].

It is often assumed that rates of prosthetic joint infections are underestimated as a result of dificulties encountered in establishing a diagnosis. Analysis of joint fluid aspirate recolted preoperatively in the presence of raised C-reactive protein combined with the analysis of intraoperative frozen sections and permanent sections for identifying active infection are new concept still limited published in literature.

The aim of the study was to determine prospectively the importance of synovial fluid white cell count (SWCC) and intraoperative frozen and permanent sections analysis (number of polymorphonuclear leukocytes per high-power field) in the diagnosis of septic total knee arthroplasty. 
Material. Methods.

There were studied prospectively 72 patients who needed a revision total knee arthroplasty between January 2013 and December 2015, hospitalised in treated in Orthopaedic-Traumatology Clinic of Constanta, Romania. From this group of patients there were 23 men and 49 women and the mean age was 72 years (range between 60 and 84 years). (table I) The interval between primary arthroplasty and revision surgery was from 1 to 12 years. Based on the levels of erythrocyte sedimentation rate and C-reactive protein and on the cultured from preoperatively joind fluid aspirate, the patients were divided in 2 groups: aseptic and septic knee prosthesis loosening.

Table I. Demographic data of patients with prosthetic joint infection (PJI) and aseptic failure (AF)

\begin{tabular}{|l|l|l|}
\hline & PJI - 30 & AF - 42 \\
\hline Median age & 74 & 69 \\
\hline Male/Female & $10 / 20$ & $13 / 29$ \\
\hline ESR*>30mm/hour & 28 & 5 \\
\hline CRP*>10mg/dl & 27 & 9 \\
\hline $\begin{array}{l}\text { Median SWCC (cells/ } \\
\mu 1)\end{array}$ & 13800 & 92 \\
\hline $\begin{array}{l}\text { Median synovial } \\
\text { neutrophile \% }\end{array}$ & 91 & 19 \\
\hline $\begin{array}{l}\text { Histology >5 PMN/ } \\
\text { HPF* on frozen } \\
\text { sections }\end{array}$ & 27 & 2 \\
\hline $\begin{array}{l}\text { Histology >5 PMN/ } \\
\text { HPF* on permanent } \\
\text { sections }\end{array}$ & 25 & 0 \\
*ESR - erytrocyte sedimentation rate, CRP-C-reactive \\
proteine, PMN/HPF - polymorphonuclear leukocytes per \\
\hline \begin{tabular}{l} 
high-power field \\
\hline
\end{tabular}
\end{tabular}

There were aspirated synovial fluid from the affected joint, under sterile circumstances, within four weeks before surgery, between 3 and $10 \mathrm{ml}$, and at least $1 \mathrm{ml}$ was inoculated in a pediatric bottle and incubated for five days. The remaining fluid was injected into an EDTA-coated tube. The cell counts were performed using a Neubauer cell counting chamber.

At the time of revision surgery were taken at least three samples of peri-prosthetic tissue, areas considered suspicious by the surgeon and tissue that was identified at the various host-implant interfaces. Frozen and permanent sections were studied with a standard staining technique with the use of hematoxylin and eosine. In all the cases, the periprothetic tissue was selected by the orthopedic surgeon, after the patients previously signed an informed consent.

After the frozen sections had been analysed, permanent sections were prepared by embedding the tissue specimen in paraffin, using the standard technique and slicing it with a microtome every three milimeters into sections that were four to five micrometers thick. The results of the histological analysis of the permanent sections were classified as negative or positive depending wether there were less than five or at least five polymorphonuclear leukocytes per high power field. The frozen section was also considered negative if there were less than five or at least five polymorphonuclear leukocytes per high power field.

The radiological exam of the affected knee showed the loosening of the tibial or femoral component of the knee prosthesis. A positive preoperative culture from joint fluid aspirate was the basic criterion for the diagnosis of infection that divided the patients into two groups: septic and aspetic failure. Comparison was made between erythocite sedimentation rate, C-reactive protein levels, culture of aspirated fluid from the joint, synovial fluid white cell count, analysis of frozen sections and permanent histological sections.

According AAOS criteria for diagnosis of joint infection we have taken in consideration the following: histological examination of tissue yelding $>$ five PMN per HPF, three or more culture samples growing identical organisms and presence of frank puss $>50000$ white cells $/ \mu 1$ and growth of a pathogenic organism $[2,3,4]$. 


\section{Results}

The patients from our study presented persistent clinical signs as pain and limitation of movement of the knee and the radiological exam showed a loosening of tibial or femoral component of the prosthesis. For all the patients was made cultures from the synovial fluid aspirated from the operated knee, and based of the cultures results, the patients were divided in 2 groups: aseptic and septic knee prosthesis loosening. In each group we analysed the corespondence of serum erytrocyte sedimentation rate, C-reactive protein levels with sinovial fluid white cells count and number of polymorphonuclear leukocytes per high-power field on histological sections taken intraoperatively.

30 patients were diagnosed with prosthetic joint infection due to high rates of ESR (93\%) and CRP (90\%) and preoperative positive culture from aspirated synovial fluid and 42 patients were considered to have aseptic failure according to negative preoperative culture from joint aspirate. From the second group, $11 \%$ had high levels of ESR and $21 \%$ had high levels of CRP.

The organisms isolated in the preoperative sinovial fluid culture were: coagulase-negative staphylococus 6, staphylococus aureus 11, enteric flora 5 (enterococci 3, escherichia coli 2), streptococus 8 . In 21 cases of periprosthetic tissue culture (intraoperatively taken) was isolated the same organism as the one we found in sinovial fluid culture.

There were statistically significant difference in sinovial fluid white cell count between the 2 groups of patients with a median of 13800 white cells $/ \mu 1$ for septic group and 92 white cells/ $\mu 1$ for aseptic group. The proportion of neutrophils is different as a median of $91 \%$ for infected knee group and 19\% for noninfected knee group.

The patients who received antibiotics at the time of joint aspiration fluid were not included in our study, so we suppose no false negative cultures preoperatively. All the patients with PJI diagnosed by positive joint fluid culture received antibiotics according to organism sensibility before revision surgery as prophylactic therapy.

Table II. Results of analysis of permanent compared with frozen sections from periprosthetic tissue samples

\begin{tabular}{|l|c|c|}
\hline Positive $>5$ PMN/HPF & $\begin{array}{l}\text { Frozen } \\
\text { sections }\end{array}$ & $\begin{array}{l}\text { Permanent } \\
\text { sections }\end{array}$ \\
\hline Group 1 (septic) - 30 & 27 & 25 \\
\hline Group 2 (aseptic) - 42 & 2 & 0 \\
\hline
\end{tabular}

The histologically sections were considered to be positive for infection when at least 5 polymorphonuclear leukocytes was found per highpower field. [1] From the group of 72 patients, 29 (40\%) had positive frozen sections and $25(34 \%)$ had positive permanent sections. From the group of patients with septic knee prothesis $27(90 \%)$ had positive frozen sections and $25(83 \%)$ had positive permanent sections.(figures 1,2,3) From the group of patients with aseptic failure $2(4.76 \%)$ had positive frozen sections and none had positive permanent sections.(table II) (figures 4, 5)

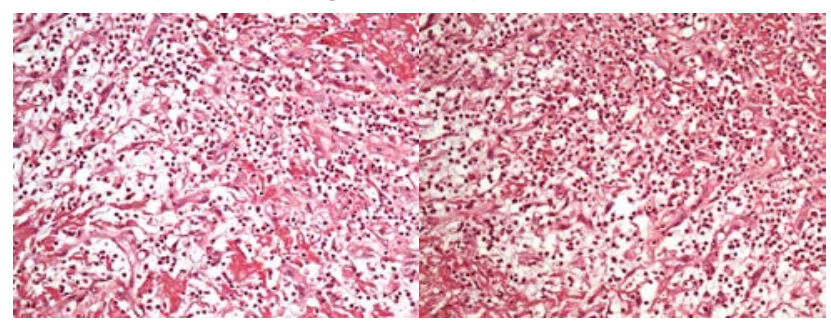

Figure 1. Septic group. Granulation tissue with minimum fibrinous exudate with a lot of polymorphonuclear leukocites (HE stained, x200)

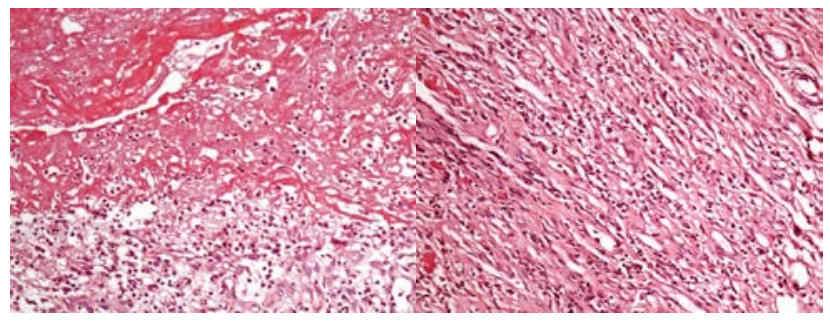

Figure 2. Septic group. Confunctive tissue with inflamatory exudate with lymphocites, plasmocytes cells and polymorphonuclear leukocites (HE stained, x200) 


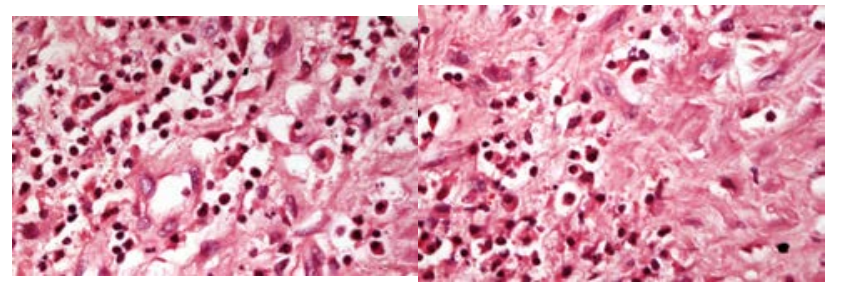

Figure 3. Septic group. Lymphocites, plasmocytes cells and numerous polymorphonuclear leukocites (HE stained, $x 400)$

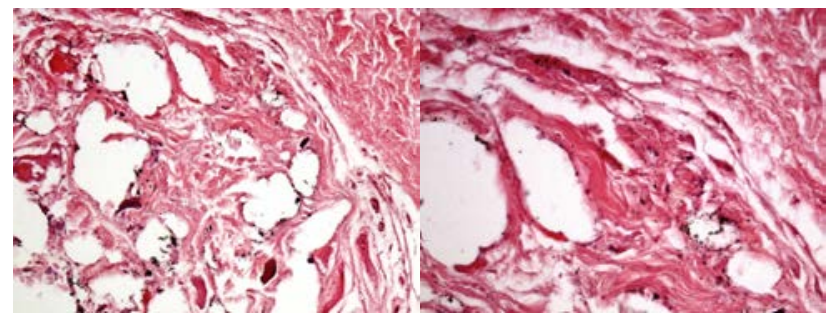

Figure 4. Aseptic group. Fat tissue with rare deposit of dark-brown pigment, absence of neutrophiles.(HE staining, x200)

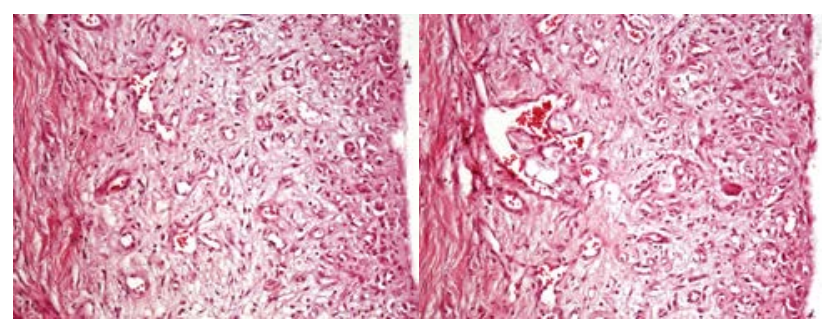

Figure 5. Aseptic group. Granulation tissue with rare polynuclear giant cells of foreign body, inflamatory tissue is poor in cells, absence of neutrophiles (HE staining, x200)

From the group of septic prosthesis diagnosed by positive preoperative culture, 24 patients $(80 \%)$ had positive culture from periprosthetic tissue taken at the time of revision surgery and for 21 patients $(70 \%)$ was isolated the same organism.(table III)
Table III. Identified microorganism that produced knee prosthesis infection

\begin{tabular}{|l|c|c|}
\hline Microorganism & $\begin{array}{c}\text { Preoperative } \\
\text { culture }\end{array}$ & $\begin{array}{c}\text { Postoperative } \\
\text { culture }\end{array}$ \\
\hline $\begin{array}{l}\text { Coagulase-negative } \\
\text { staphylococ }\end{array}$ & 6 & 2 \\
\hline Staphylococ aureus & 11 & 11 \\
\hline Enteric flora & 5 & 2 \\
\hline Streptococ & 8 & 6 \\
\hline Pseudomonas & 0 & 3 \\
\hline
\end{tabular}

From the septic group of patients, 3 cases had negative frozen sections and 5 patients had negative permanent sections, all these cases being considered false negative.

All the patients from the group 1 (septic prosthesis) which primary diagnosis of infection was based on lab parameters of infection (high rate of ESR and CRP) and preoperative positive culture of joint fluid aspiration, were treated by staged revision surgery: first stage was implant removal and antibiotic spacer implantation and second stage (after a period of at least 6-8 weeks of antibiotherapy and normalisation of ESR and CRP) with prosthesis implantation.

The patients from the second group (aseptic loosening) were treated by primary exchange of the implant. The two cases from this group which had positive frozen sections were considered false positive results, decision confirmed by negative permanent sections and no positive culture from the periprosthetic sections taken intraoperatively. Due to a lack of long-term evaluation of these groups, further follow-up is needed to confirm the accuracy of diagnosis. 


\section{Discussion}

Failure of total knee arthroplasty due to infection can occur more rarely as due to aseptical mechanical loosening, but the treatment for septic loosening is a dificult job for the surgeon and sometimes with unsuccesfully end. For the diagnosis of infection, the clasically clinical signs can be missing (fever, swelling, erythema, drainage). The determination of the erytrocyte sedimentation rate and C-reactive proteine level can be valuable for the diagnosis and the preoperative joint aspirate culture can confirm the infection. The diagnose of infection in the septic group of patients was based primary on joint aspirate culture. The important rates of false positive or false negative results on preoperative cultures of aspirate reported in literature impose to find more diagnostic criteria with higher specificity for the diagnosis of joint infection $[5,6,7,8]$.

Table IV. White cell counts in aspirated joint fluid

\begin{tabular}{|l|c|c|}
\hline Reference & $\begin{array}{l}\text { Units used in } \\
\text { study }\end{array}$ & $\begin{array}{l}\text { Conversion in } \\
\text { cells } / \mu 1\end{array}$ \\
\hline Spangehl et al. & $50 \times 10^{9} / \mathrm{L}$ & 50000 \\
\hline Kersey et al. & $2000 / \mathrm{ml}$ & 2 \\
\hline Mason et al. & $2500 / \mathrm{ml}$ & 2.5 \\
\hline Trampuz et el. & $1.7 \times 10^{3} \mu \mathrm{L}$ & 1700 \\
\hline
\end{tabular}

In the absence of a joint implant, measurements of the concentration of leukocytes and the proportion of those leukocytes that are neutrophils in synovial fluid are important tests to help distinguish among osteoarthritis, infection, and noninfectious inflammatory arthropathies. Several studies have indicated that cell counts of fluid aspirated from around total joint prostheses can also provide useful information, although the literature is somewhat difficult to interpret, in part because authors have used different units of volume to express values. As seen in table IV, the disparity in reported cell concentrations suggests that some authors may not have reported the correct units of volume. Setting aside the inconsistencies in units, there are still discrepancies with regard to the level at which the cell count in fluid from the site of a prosthetic joint may be considered abnormal. From a practical standpoint, we consider a white blood-cell count of $>500 / \mu \mathrm{L}$ as suggestive of periprosthetic infection $[9,10,11,12,13]$.

The analysis of sinovial fluid white cell count, of the intraoperative frozen sections and permanent sections has been found to be more accurate diagnostic method for guiding the surgeon. The number of polymorphonuclear leukocytes per high power field (more than 5) on histological sections of periprosthetic tissue taken intraoperatively seem to be a good indicator of infection $[14,15]$.

Probably the first study of the use of frozen sections to diagnose an infection at the site of an arthroplasty was reported by Charisky et al. in 1973. Those authors described the results of analysis of frozen sections on implant membranes obtained from twenty patients, ten of whom had intraoperative cultures that were positive for organisms and ten of whom had intraoperative negative cultures. Of the ten with positive cultures, five had acute inflammation that was " $2+$ or greater" (not otherwise defined) and the other five had chronic inflammation that was " $2+$ or greater". The authors concluded that acute inflammatory changes or "severe chronic inflammation" were presumptive evidence of infection [15].

Table V. Histologic criteria for interpretation of frozen sections as diagnostic of infection

\begin{tabular}{|l|l|}
\hline Reference & Criteria \\
\hline Mirra et al. & $\begin{array}{l}>5 \text { neutrofils in }>5 \text { high-power } \\
\text { fields*, excluding surface fibrin and } \\
\text { inflammatory exudates }\end{array}$ \\
\hline $\begin{array}{l}\text { Abdul-Karim } \\
\text { et al. }\end{array}$ & $\begin{array}{l}>5 \text { neutrofils in }>5 \text { high-power } \\
\text { fields, excluding surface fibrin and } \\
\text { inflammatory exudates }\end{array}$ \\
\hline Fehring et al. & $\begin{array}{l}>5 \text { polymorphonuclear leukocytes per } \\
\text { high power field in }>5 \text { high power } \\
\text { fields }\end{array}$ \\
\hline $\begin{array}{l}\text { Fehring and } \\
\text { McAllister }\end{array}$ & $\begin{array}{l}\text { Evidence of acute inflammation (no } \\
\text { quantification) }\end{array}$ \\
\hline Charosky et al. & Acute or marked chronic inflammation \\
\hline Lohner et al. & $\begin{array}{l}>10 \text { polymorphonuclear leukocytes } \\
\text { per high power field in }>5 \text { high power } \\
\text { fields }\end{array}$ \\
\hline
\end{tabular}




\begin{tabular}{|l|l|}
\hline $\begin{array}{l}\text { Athanasou et } \\
\text { al. }\end{array}$ & $\begin{array}{l}>5 \text { polymorphonuclear leukocytes, } \\
\text { lymphocites or plasma cells per high } \\
\text { power field in }>10 \text { high power fields }\end{array}$ \\
\hline Pandey et al. & $\begin{array}{l}\text { One inflammatory cell per high power } \\
\text { field in }>10 \text { high power fields }\end{array}$ \\
\hline Spangehl et al. & $\begin{array}{l}>5 \text { stromal neutrophils in any single } \\
\text { high power field }\end{array}$ \\
\hline Banit et al. & $\begin{array}{l}>10 \text { polymorphonuclear leukocytes } \\
\text { per high power field in }>5 \text { high power } \\
\text { fields }\end{array}$ \\
\hline $\begin{array}{l}\text { The high power field defined in this study was 500x. the } \\
\text { high power field in all other studies was 400x or was } \\
\text { not specified. }\end{array}$ \\
\hline
\end{tabular}

As described in the studies summarized in Table V, criteria for interpretating microscope slides of frozen sections are not yet uniform. Considering a low number of neutrophils (one cell per high power field) to be diagnostic for infection will be associated with false positive diagnoses and hence decreased specificity. Use of more stringent criteria (5 polymorphonuclear per high power field in at least 5 fields) will improve specificity of diagnosis. Numeric criteria are complicated even more by differences in the visual field size of different microscopes. While most authors have used 10x ocular and 40x objective lenses (yielding a nominal net magnification of 400x), other differences in microscope and camera configurations can vary the visual field by as much as twofold. Therefore, the number of inflammatory cells per high power field should be recognised as only an approximation $[1,10,15,16,17,18,19,20]$.

The results of our study showed a median value of 13800 of sinovial white cells count for infected knee and 92 for noninfected knee. The analysis demonstrated to be a higly discriminatory test for the diagnostic of joint infection. Our study demonstrates also the relation of preoperative ESR (93\% group 1 and 4,7\% group 2) and CRP (90\% group 1 and $21 \%$ group 2) with the incidence of infected knee arthroplasty.

$90 \%$ of the patients with joint infection had more than 5 polymorphonuclear leukocytes per high power field on intraoperative frozen sections and $83 \%$ on permanent sections. None of the patients from aseptic group had more than 5 polymorphonuclear leukocytes per high power field on permanent sections.
The determination of number of polymorphonuclear leukocytis per high power field on intraoperative sections and permanent sections seem to be a good indicator for active infection.

False positive frozen sections (those associated with negative intraoperative cultures) may be due to one of several causes: a fastidious organism that fails to grow in vitro, culture and frozen-section specimens that were taken from different areas, or the presence of a loculated infection. Discrepancy between samples sent for a histological analysis and those used for cultures, as well as a bacteriological contamination of the specimen obtained for culture, may account for the false negative frozen sections (those associated with positive cultures) [1].

The value of diagnostic methods of joint infection in a total knee arthroplasty evaluated in our study can be valuable in the cases when tipical diagnosis based on clinical and paraclinical parameters are poor. The erytrocyte sedimentation rate and C-reactive protein levels have specificity for infection only at high levels. Allthough these tests are not diagnostic for infection, they are adequate for screening and ruling out infection because of their high negative predictive value.

\section{Conclusions}

Periprosthetic total knee arthroplasty infections remain difficult to diagnose and treat. Diagnosis is based on a combination of clinical findings, serological tests, imaging and laboratory findings. Preoperative arthrocentesis is a valuable procedure for the investigation of septic and aseptic failed knee arthroplasties. Synovial samples can be tested for white blood cell count, Gram staining and full microbiological culture. Elevated ESR and CRP with a synovial fluid white cell count $>13000 / \mu l$ is a great indicator of prosthetic knee infection.

Histopathological examination ofintraoperative samples could provide additional information to the 
diagnosis of prosthetic joint infection. A neutrophil count $>5$ cells per high power field, at a magnification $\mathrm{x} 400$ has a good specificity for predicting prosthetic joint infections and can be used to decide between the need for primary revision or staged revision when other preoperative evaluation has failed to confirm infection. Frozen sections analysis is a valuable tool to support the diagnosis of prosthetic joint infections while the surgeon remains in the operating room, with the results being avaible within 30 minutes, compaired to one or more days for permanent histopathology.

\section{References}

1. Lonner, J.H., Desai, P., Dicesare, P.E., Steiner, G. \& Zuckerman, J.D. (1996). The reliability of analysis of intraoperative frozen sections for identifying active infection during revision hip or knee arthroplasty. J Bone Joint Surg Am, 78(10), 1553-1558.

2. Dinneen, A., Guyot, A., Clements, J. \& Bradley, N. (2013). Synovial fluid white cell and differential count in the diagnosis or exclusion of prosthetic joint infection. Bone Joint J, 95-B(4), 554-557. doi: 10.1302/0301-620X.95B4.30388

3. Della Valle, C., Parvizi, J., Bauer, T.W., Dicesare, P.E., Evans, R.P., Segreti, J., Spangehl, M., Watters, W.C., 3rd, Keith, M., Turkelson, C.M., Wies, J.L., Sluka, P. \& Hitchcock, K. (2010). Diagnosis of periprosthetic joint infections of the hip and knee. J Am Acad Orthop Surg, 18(12), 760-770.

4. Mirra, J.M., Amstutz, H.C., Matos, M. \& Gold, R. (1976). The pathology of the joint tissues and its clinical relevance in prosthesis failure. Clin Orthop Relat Res(117), 221-240.

5. Cherney, D.L. \& Amstutz, H.C. (1983). Total hip replacement in the previously septic hip. $J$ Bone Joint Surg Am, 65(9), 1256-1265.

6. Feldman, D.S., Lonner, J.H., Desai, P. \& Zuckerman, J.D. (1995). The role of intraoperative frozen sections in revision total joint arthroplasty. J Bone Joint Surg Am, 77(12), 1807-1813.

7. Fitzgerald, R.H., Jr., Nolan, D.R., Ilstrup, D.M., Van Scoy, R.E., Washington, J.A., 2nd \& Coventry, M.B. (1977). Deep wound sepsis following total hip arthroplasty. $J$ Bone Joint Surg Am, 59(7), 847-855.

8. McDonald, D.J., Fitzgerald, R.H., Jr. \& Ilstrup, D.M. (1989). Two-stage reconstruction of a total hip arthroplasty because of infection. $J$ Bone Joint Surg Am, 71(6), 828-834.

9. Schumacher, H.R. Jr, Klippel, J.H. \& Koopman, W.J. (1993). Primer on the rheumatic diseases. 10th ed. Atlanta: The Arthritis Foundation

10. Spangehl, M.J., Masri, B.A., O'Connell, J.X. \& Duncan, C.P. (1999). Prospective analysis of preoperative and intraoperative investigations for the diagnosis of infection at the sites of two hundred and two revision total hip arthroplasties. J Bone Joint Surg Am, 81(5), 672-683.

11. Kersey, R., Benjamin, J. \& Marson, B. (2000). White blood cell counts and differential in synovial fluid of aseptically failed total knee arthroplasty. J Arthroplasty, 15(3), 301-304.

12. Mason, J.B., Fehring, T.K., Odum, S.M., Griffin, W.L. \& Nussman, D.S. (2003). The value of white blood cell counts before revision total knee arthroplasty. J Arthroplasty, 18(8), 1038-1043.

13. Trampuz, A., Hanssen, A.D., Osmon, D.R., Mandrekar, J., Steckelberg, J.M. \& Patel, R. (2004). Synovial fluid leukocyte count and differential for the diagnosis of prosthetic knee infection. Am J Med, 117(8), 556-562. doi: 10.1016/j.amjmed.2004.06.022

14. Bullough, P.G. (1973). Tissue reaction to wear debris generated from total hip replacements. The hip. Proceedings of the first open scientific meeting of the hip society, 80-91, St Louis, C.V. Mosby

15. Charosky, C.B., Bullough, P.G. \& Wilson, P.D., Jr. (1973). Total hip replacement failures. A histological evaluation. $J$ Bone Joint Surg Am, 55(1), 49-58.

16. Athanasou, N.A., Pandey, R., de Steiger, R., Crook, D. \& Smith, P.M. (1995). Diagnosis of infection by frozen section during revision arthroplasty. J Bone Joint Surg Br, 77(1), 28-33. 
17. Abdul-Karim, F.W., McGinnis, M.G., Kraay, M., Emancipator, S.N. \& Goldberg, V. (1998). Frozen section biopsy assessment for the presence of polymorphonuclear leukocytes in patients undergoing revision of arthroplasties. Mod Pathol, 11(5), 427-431.

18. Fehring, T.K. \& McAlister, J.A., Jr. (1994). Frozen histologic section as a guide to sepsis in revision joint arthroplasty. Clin Orthop Relat Res(304), 229-237.

19. Pandey, R., Berendt, A.R. \& Athanasou, N.A. (2000). Histological and microbiological findings in non-infected and infected revision arthroplasty tissues. The OSIRIS Collaborative Study Group. Oxford Skeletal Infection Research and Intervention Service. Arch Orthop Trauma Surg, 120(10), 570-574.

20. Banit, D.M., Kaufer, H. \& Hartford, J.M. (2002). Intraoperative frozen section analysis in revision total joint arthroplasty. Clin Orthop Relat $\operatorname{Res}(401), 230-238$. 